\title{
The bearable lightness of all glass structures.
}

\author{
Rob NIJSSE \\ Civil Engineer \\ ABT / Tech. University \\ Delft, the Netherlands \\ r.nijsse@tudelft.nl
}

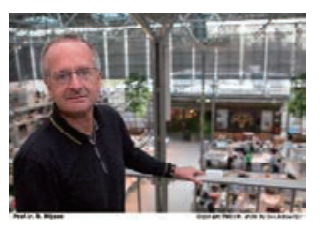

Rob Nijsse, born 1953, received his civil engineering degree from the University of Delft, the Netherlands. He works for Consultants Company ABT, Arnhem, NL and became in 2007 Professor at the University of Delft, NL. His main area of research is related to new developments in structural engineering, especially in Glass..

\section{Summary}

This paper is new developments in structural engineering related especially to the use of the material glass. After a philosophical discussion about why glass is the material for the Future, all glass elements and related techniques are presented from which an all glass building can be assembled. To conclude this paper, all glass structures like a glass bridge, glass columns, a glass brick wall and a corrugated glass faced are shown in realised projects.

Keywords: glass structures, sustainability, innovation.

\section{Philosophical discussion.}

Glass is a mysterious material. On the one hand it is transparent: about $95 \%$ of the light passes unhindered through a $10 \mathrm{~mm}$ thick glass plate, on the other hand : water cannot pass through the glass. I don't know any other material that has these contradicting properties. More over: if the wind blows your wineglass over, it breaks, but in laboratorial conditions we have put a stress level of $500 \mathrm{MPa}$ (in tension!) in a carefully prepared glass bar. If we realise that glass is basically made from $75 \%$ (molten) sand and 25\% chalk and soda, all three abundant materials on Earth, and can be recycled $100 \%$, it is a sustainable material indeed. Furthermore it does not rot, it does not corrode and can be cleaned easily with water. Plentiful considerations to look at glass like the building material of the Future.

These are, however, all technically driven considerations, there are also sociological important arguments. And that begins with the gift of transparency that glass gives us, humans. We can look from inside to outside, almost unhindered, but protected, by the glass, from wind, cold and rain. Also we can look from inside into the buildings and are able to notice what is going on inside the buildings. Modern, democratic society calls for transparent behaviour of all participants in our society and the fact that everybody is able to see what is going on inside any building that is cladded with glass in the facades gives a remarkable boost to the controllability and the responsibility of each participant in society. Of course the need for privacy is a naturally felt fact and we don't want to live in a-" 1984 "- like world with $24 \mathrm{~h} / 7 \mathrm{~d}$ control by the authorities. But if you decide to close the curtains or shutters you make a statement that you are out of the control of society and therefore are not any more transparent in a sociological way. This is a modern and most complicated discussion: what is to be preferred? Transparency or Privacy? It is my conviction that if you look at the possibilities that the modern, Internet offers us, our modern computer based society is already almost $100 \%$ transparent, like it or not. 


\section{Elements and techniques to make an all glass building/ bridge.}

\subsection{Elements.}

The glass industry produces a limited area of possible elements, especially if we look at industrial products. Basically everything is made from standard size flat glass panels measuring max. 6 by 3.2 meter in thicknesses varying from 3 to $24 \mathrm{~mm}$. There are developments, especially in China, where bigger sizes are possible but the related price level is still very high. Other shapes that are produced in an industrial scale are massive bars and cylinders produced, mostly for the chemical industry. An important producer of these objects is Schott from Germany.

\subsection{Techniques.}

The flat panels of glass mentioned in the last paragraph can be manipulated with the following techniques:

-cutting in any size or shape you like, preferred is water jet cutting that gives the best results for the smoothness of the edges of the, new, flat, panel.

- adhesive- based assembly, by means of a layer of glue (to be hardened after applying to the glass surface) two individual panels can be fixed to form a strong unit.

- hot forming, If you heat up glass to around 800 degrees Celsius, the glass will become vicious, syrup like if you wish, and it starts to deform due the forces of gravity. If we place a flat glass panel of the correct size on a mould in the required shape, heat the furnace up to 800 degrees Celsius, the glass panel will melt over the mould and take the shape of the mould. Slowly cooling down to avoid shrinkage caused stresses is necessary but the result will be a 3D deformed glass panel in the shape you want.

\section{Realised glass structures with the elements and the techniques mentioned.}

As an example to show the new opportunities that the glass elements and the techniques mentioned in paragraph 2 present, we will give you four projects in which this was realised. That are: a bridge between two buildings made completely out of glass, an all glass column, a façade made out of glass bricks and facades for modern Architecture buildings made out of hot formed glass panels.

\subsection{All glass bridge.}

In the Arnhem (NL) zoo there was a need for a connecting bridge to made between two, existing buildings, one in wood, the other in brickwork, and the architect could not decide what material to use, wood or bricks or even steel? After some sleepless nights he/she thought: what if I make it out of glass? Nobody will notice it and I have made an almost invisible connection. So ABT was summoned to realise this idea, technically.

Literally this means transforming each basic structural element of a building, the floors, the walls, the roofs and the facades in an all glass one. So the floor was made out of glass panels laying on two glass beams, the walls were just two panels of laminated glass and on these two walls, or facades, a single curved glass panels was glued as roof. There was also a height difference between the two buildings that resulted in the need for a stair, that, naturally, was made out of glass steps and treads as well. 


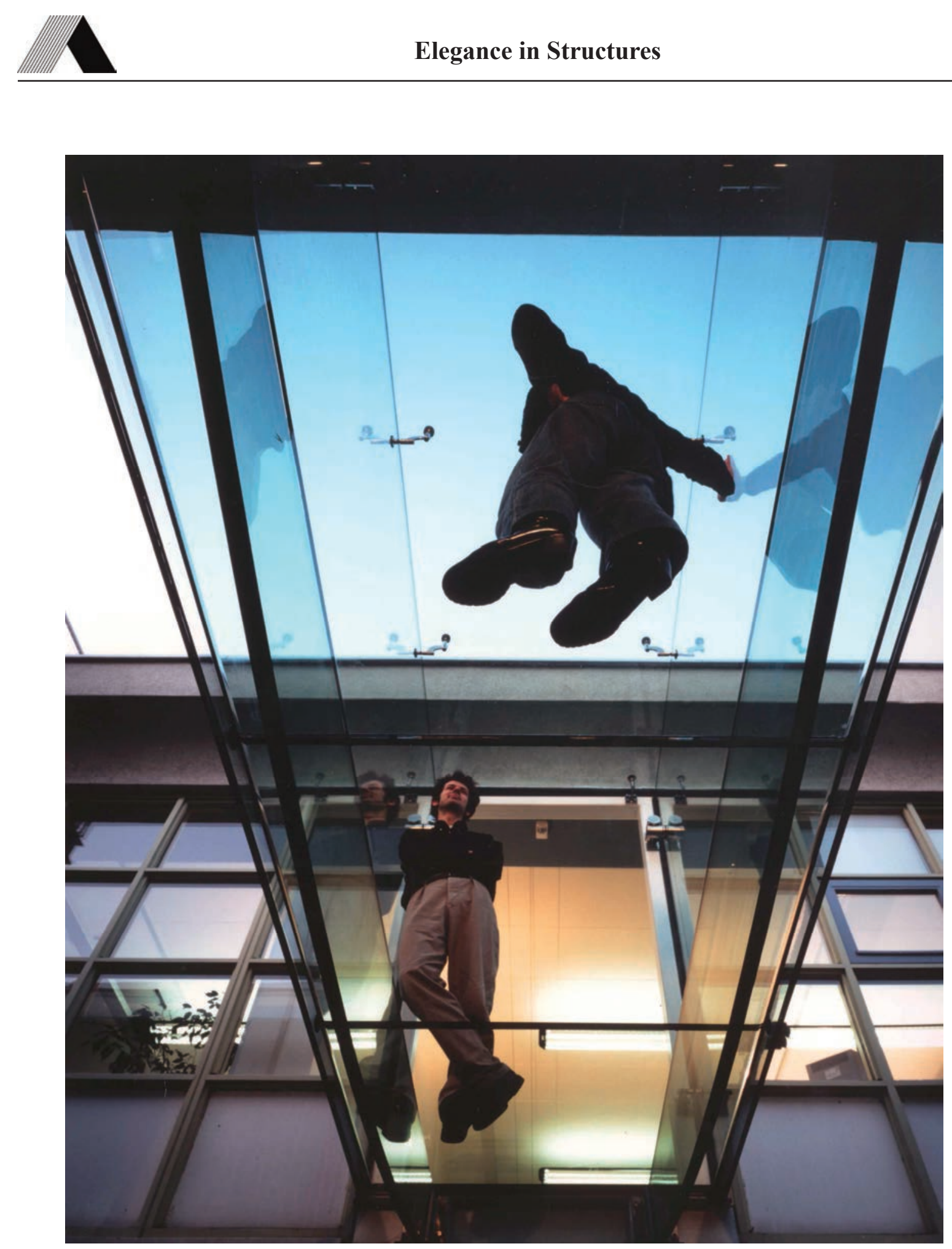

Fig. 1 Glass bridge Rotterdam (arch. Kraayvanger). Glass enables a 3D view of an building. 
The people that see this all glass bridge for the first time may wonder if it is a safe one as well, for let's be honest, even I feel a discomfort able feeling when I set my first foot on the glass. In our mind the sense of being not visually supported by something solid and sound makes our minds go anxious. However the engineers of the world have the moral responsibility to create safe, reliable structures that people may use without having to worry about safety issues. Luckily enough, mostly thanks to the concept of laminated glass panels, we are able to create safe, all glass structures. The proof is in the picture below where the connecting, all glass stair on the other side of the building, with no stair in it, was heavily damaged by an incautious forklift truck driver that completely drove away the two glass beams that carry the floor. Secondary structural systems still hold the bridge together to be able to make the crossing still. With a reduced safety factor, of course.

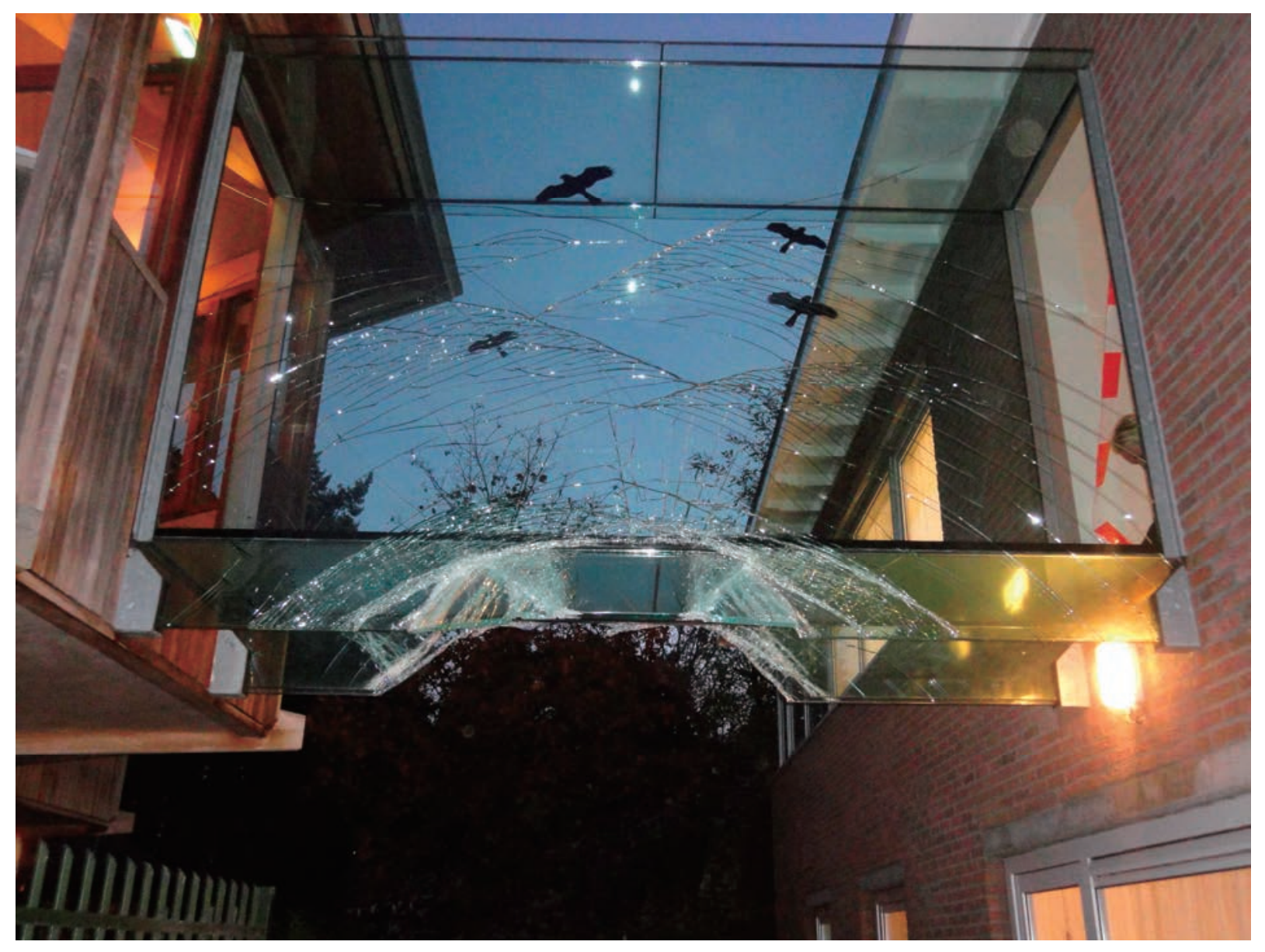

Fig. 2, A broken but still functioning glass bridge like the Rotterdam one of fig. 1. 


\subsection{Bundle of Glass bars: an all glass Column.}

Studies have been made by ABT and the Technical University of Delft into the possibility to create a safe glass column. Glass in compression is very strong and stiff; therefore it would be an ideal material for a column, certainly if we take its natural transparency into account. Columns are never treated with respect: for an architect they block the view and for a client they stand in the way. Mentioned before was a safe glass column and that is done on purpose since columns are crucial elements of the main bearing structure of a building. They have to be, according to the Euro-codes, robust. That means that, if a maleficent person attacks the column with a sledgehammer, just one blow of this sledgehammer may not break the complete column and, as a result, will bring down the whole building on top of the column. We all know that a single piece of glass will break and fall apart completely with the first blow and that is why a safe glass column must be composed of a large number of glass elements that are connected together to form the safe glass column. We found out that a bundle of massive glass bars are the ideal way to create a strong and very safe glass column. An architect gave me a more psychological reason: a bundle of glass bars is very visible, very present. This means that people will see the glass column and therefore will think, ah ha, there is the column that carries everything and will not look around in amassment to find where the columns are. We tested the massive bar bundle type of glass column in the Stevin II laboratory of the Technical University of Delft (NL). A 1.5 meter tall column with a diameter of around $70 \mathrm{~mm}$ could take an average compression load of $150 \mathrm{~N} / \mathrm{mm} 2$ before a buckling affiliated failure began to start. 


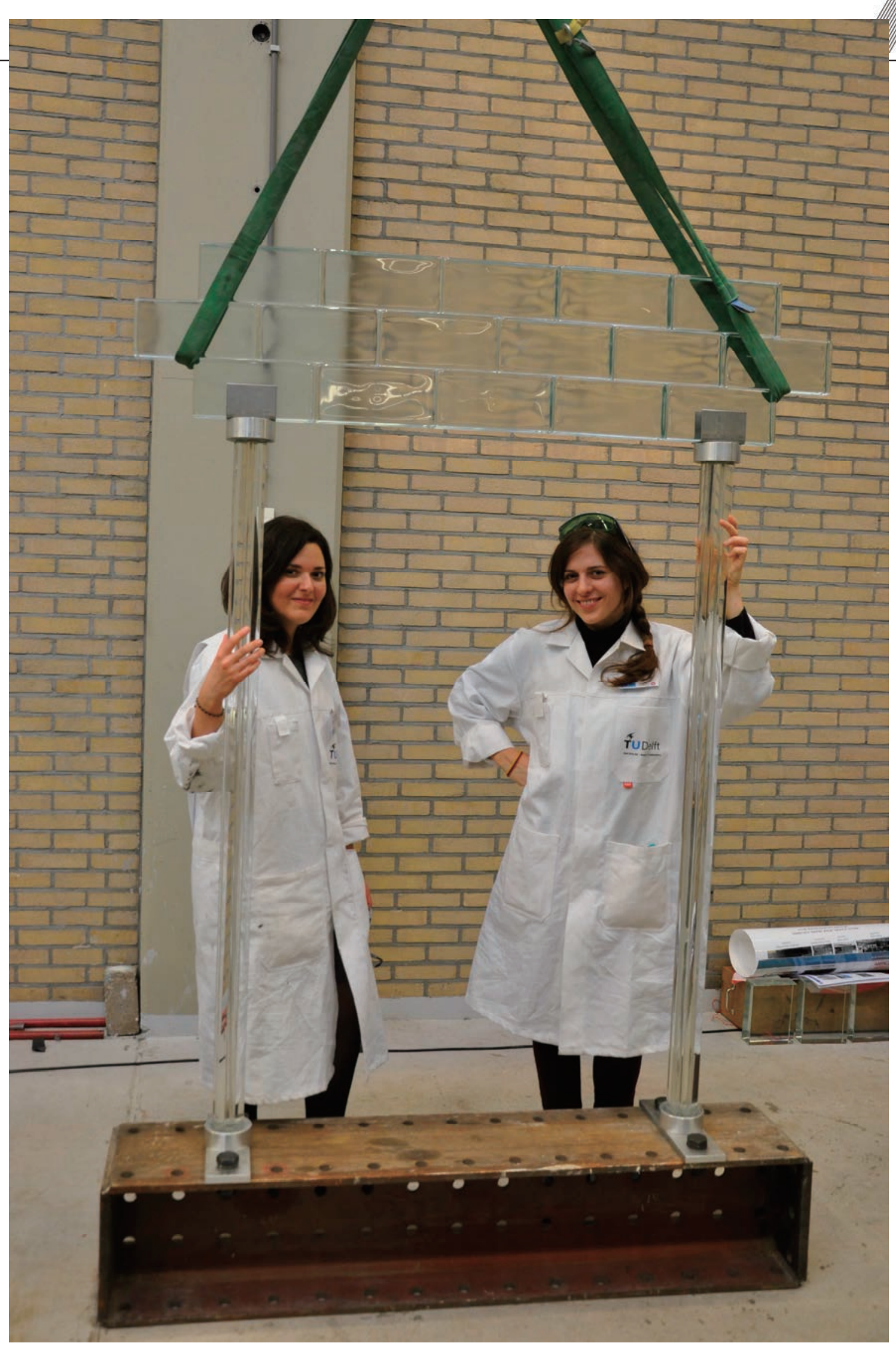

Fig. 3, All glass portal, two bundle columns and a glass brick tapered beam om top, at the TU in Delft (NL). 


\subsection{Glass cast elements.}

As stated in the introduction glass can be melted and poured like a liquid/ syrup-like fluid in a chosen formwork. After solidification of the glass the shape of the glass element will be identical to the shape of the formwork. Sounds simple but reality proves that this process is quite complicated. This is caused by unequal cooling down of parts of the glass elements for instance the surface compared to the inside of the elements. Unequal cooling results in difference in shrinking and therefore in unacceptable levels of stresses in the material glass. This inevitable will lead to cracking and even falling apart of the glass elements. Careful and controlled cooling down of the just poured in glass in the formwork is necessary to somehow control this inevitable physical production process

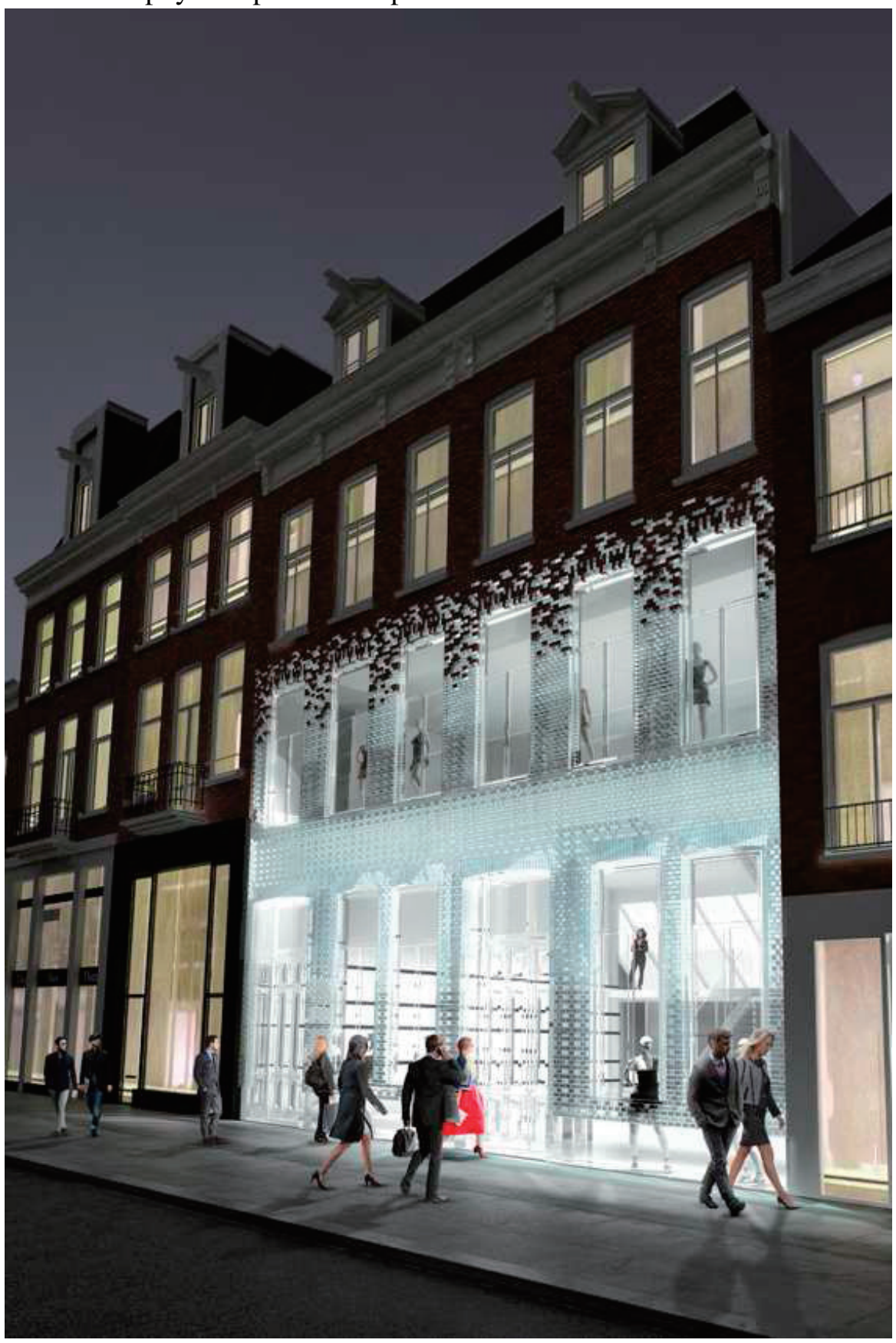

Fig. 4. All glass brick façade for the Chanel shop in Amsterdam (arch. MVRDV) 


\subsection{Hot formed glass panels, curved surfaces.}

One can use the property of glass to lose its shape when heated over 800 degrees Celsius to let, in a furnace, a flat glass "melt" over a chosen form: a mould. If the measurements of the flat glass panel are correctly established; any shape can be made: flat, single curved, three dimensionally curved , only a minimum curvature of about $50 \mathrm{~mm}$ radius has to be respected. Also the sizes of the furnace limit the dimensions of the obtained glass panels, or should I say " shape".

We used this strategy to make large glass facades with as less as possible steel support structure. A corrugated (= wave like pattern) surface is much stronger and stiffer then a flat surface. A simple piece of paper folded over a few times demonstrates this convincingly.

We realise now two buildings with this strategy: the Casa da Musica in Porto (P) by OMA architects and the Museum at the Stream in Antwerp (B0 by Neutelings Riedijk architects. Two projects are almost finished; the University Library in Doha (Qatar) and the Theatre in Taipei (Taiwan), both by OMA architects.

Studies are planned to use the corrugated glass panels as floor- and roof elements. Also there is an initiative to use an upstanding corrugated glass panel as load bearing wall.

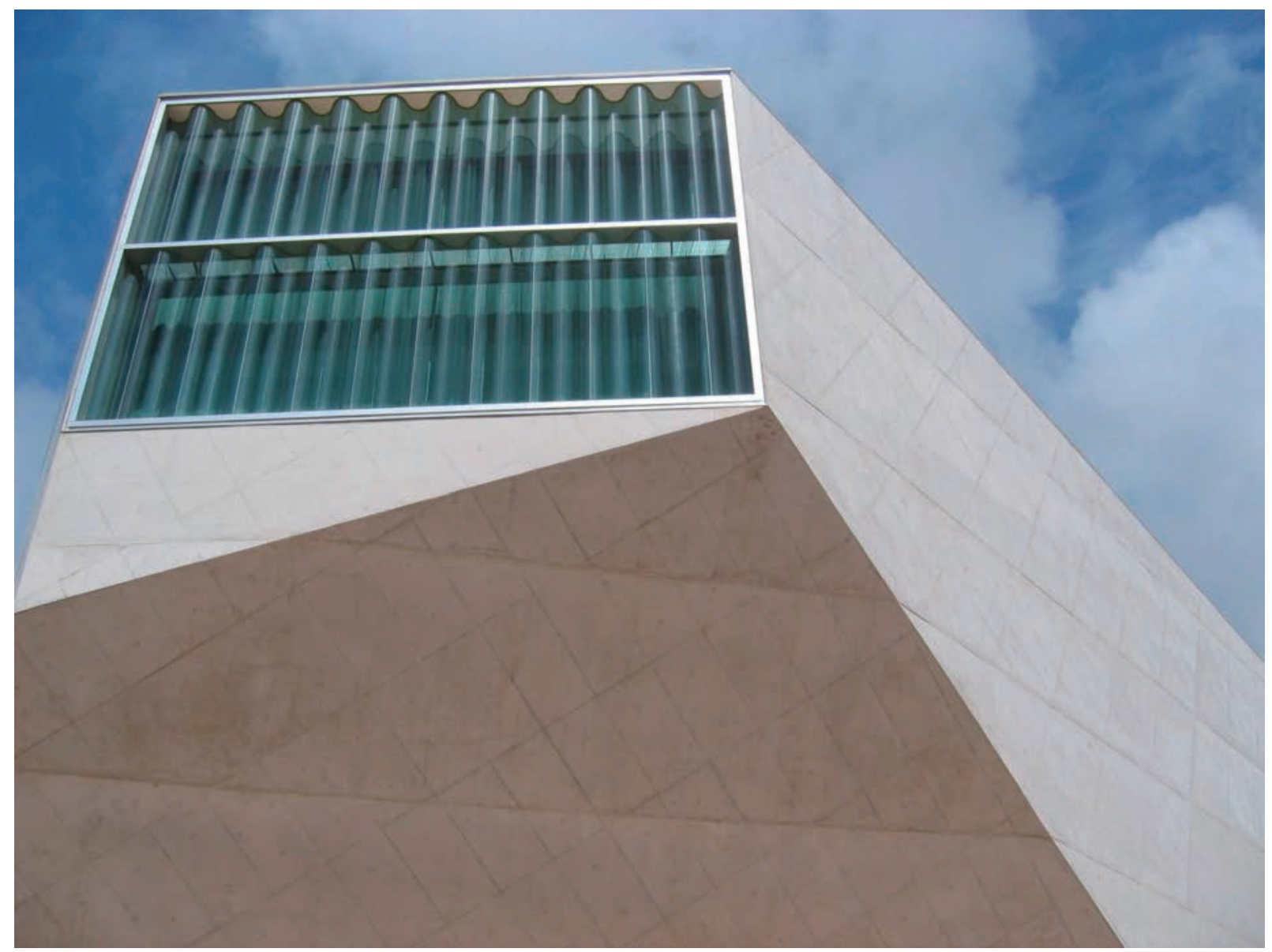

fig. 5. Corrugated glass facade of the Casa da Musica in Porto, (arch. OMA). Notice the lively, shining glass compared to the quiet and cold concrete. 